\title{
A ESSÊNCIA LEITORA DO PROFESSOR COMO INFLUÊNCIA PARA A FORMAÇÃO DE ALUNOS LEITORES
}

\author{
Hádrya Jacqueline da Silva Santos ${ }^{1}$ \\ Solange Santana Guimarães Morais ${ }^{2}$
}

\begin{abstract}
Resumo: Este artigo se compromete a destacar o papel do professor na formação leitora dos alunos, principalmente se aquele for um leitor ativo. Sabe-se, portanto, que é no âmbito escolar que a leitura deve ser cada vez mais aprimorada, tendo o docente como ferramenta essencial nesse processo. Além disso, é de suma importância que se avaliem os fatores que muitas vezes impossibilitam a prática e o incentivo à leitura por parte do professor. Assim, para melhor dissertar sobre o assunto, o estudo conta com contribuições de Isabel Solé (1998), Ezequiel Theodoro da Silva (1987), Pedro Demo (2006), Marisa Lajolo (1993), Marcos Bagno (2006), entre outros pesquisadores. Esta pesquisa é relevante por repensar a importância do professor como mediador de leituras, contribuindo para o melhoramento das metodologias a serem trabalhadas no processo de incentivo à leitura, além de fornecer sugestões metodológicas que podem ser aproveitas pelo docente durante a sua prática de ensino.
\end{abstract}

Palavras-Chave: Aluno. Leitura. Professor.

\section{Introdução}

A sociedade se encontra em um processo constante de mudanças e, paralelo a isso, a tecnologia também se desenvolve, quem sabe até mais rapidamente. A leitura não se isenta desse processo de desenvolvimento, uma vez que ela pode passar por atualizações na medida que tudo ao seu redor se modifica. Dessa forma, falar de práticas de leituras não deve consistir em um assunto desagradável, sendo que a partir dessas práticas é possível obter-se uma melhor percepção de mundo, o que contribui fortemente para as formações intelectual e pessoal do indivíduo.

O interesse em estudar sobre tal assunto se deu a partir da percepção de que muitos dos sujeitos responsáveis pelo ensino da leitura, no âmbito escolar, não se preocupam em despertar no aluno o prazer em ler. Não significa dizer que os alunos não leem, pelo contrário, eles leem, sim, mas, na maioria das vezes essa leitura caracteriza-se como obrigatória, em que o que é lido serve apenas para

\footnotetext{
${ }^{1}$ Licenciada em Letras - Literaturas pela Universidade Estadual do Maranhão - UEMA, Campus Caxias. E-mail: hadryassantos@hotmail.com e/ou hadrya.jack@gmail.com;

2 Professora Doutora em Ciência da Literatura (UEMA/UFRJ). Diretora do Curso de Letras (CESCUEMA). Coordenadora do NuPLIM - CNPq. Trabalha na área de Literatura, Teoria Literária e Literatura Maranhense pelo Departamento de Letras do CESC/UEMA. Editora da Revista de Letras Juçara. E-mail: sogemorais@bol.com.br e sogemorais@gmail.com.
}

Revista de Letras JUÇARA, Caxias - Maranhão, v. 03, n. 02, p. 143 - 159, dez. 2019| 143 
corresponder às atividades propostas em sala de aula. Além disso, nota-se que muitos alunos ainda apresentam dificuldades ao ler e interpretar um texto, e infelizmente as aulas de Língua Portuguesa não têm o ensino e a prática de leitura como prioridades, sendo os conteúdos gramaticais os mais trabalhados durante as aulas.

Inúmeros são os estudos que denunciam a falta de incentivo à leitura como um grande problema, e essa ausência se dá por fatores diversos. Embora haja investimentos em materiais de leitura no Brasil, os resultados de provas aplicadas tanto aos alunos quanto aos professores não são satisfatórios, o que leva-nos a crer que o problema não se concentra apenas nos alunos.

Os livros sozinhos não são capazes de formar leitores, é necessário que hajam mediadores de leitura, pessoas que têm a leitura como paixão e que alimentem o hábito de ler. Só assim é que poderão disseminar a leitura para que outras pessoas também sejam conhecedoras desse universo. E, assim, supondo que a escola disponha de todos os quesitos necessários para a efetivação da prática de ensino da leitura, é indispensável a existência de professores leitores.

Para a elaboração deste estudo, apoiamo-nos nas reflexões de Silva (2003), Lajolo (2005), Demo (2006), Solé (1998), Simões (2006), entre outros, visando obter informações acerca das práticas docentes, no que diz respeito à leitura. A pesquisa serviu para responder questões norteadoras, como: Quais estratégias de leitura podem ser utilizadas para incentivar os alunos a lerem? Como o professor pode selecionar obra e/ou textos para desenvolver a prática de leitura dos alunos? Quais fatores podem atrapalhar na prática da leitura?

A leitura é a chave que abre novas portas aos alunos, ampliando seus conhecimentos e possibilitando que eles se posicionem criticamente diante da realidade em que estão inseridos. Portanto, da mesma forma que o professor é capaz de transmitir todo tipo de conhecimento aos alunos, ele também pode ensinálos a entender a leitura como prática fundamental para a formação cidadã e para a integração desse cidadão no universo literário.

Em vista disso, o que se pretende é investigar e entender o problema, ao passo que se buscam estratégias capazes de contribuir para o melhoramento da realidade da leitura e possibilitar uma prática reflexiva aos professores e pesquisadores da área.

Revista de Letras JUÇARA, Caxias - Maranhão, v. 03, n. 02, p. 143 - 159, dez. 2019|144 


\section{Breves considerações sobre leitura}

O ato de ler é, de fato, uma grande (talvez maior) experiência da vida escolar de uma pessoa. Dominar a leitura, além de permitir ao indivíduo a aquisição de novos conhecimentos, possibilita também que ele participe ativamente da sociedade em que se vive, permitindo-lhe desenvolver uma visão de mundo não apenas do seu "universo particular", bem como do mundo do outro. Talvez por isso é que Silva (2003, p. 96) afirma que "ler em si não é viver. Ler é conseguir o devido combustível de ideias para viver em sociedade".

Por entender a leitura como uma forma de responder questionamentos acerca de experiências existenciais, é que Martins (1994, p. 17) apresenta-nos inúmeras finalidades da leitura e a destaca como essencial para "desvendar os segredos do mundo e dar a conhecer o leitor a si mesmo através do que lê e como lê". A prática leitora possibilita a produção de ideias, atiçando no leitor o desejo de mudar a si mesmo ou algo ao seu redor.

Constata-se que a leitura realmente permite ao indivíduo se autoconhecer e que ler um texto, seja ele verbal ou não-verbal, possibilita uma melhor percepção do mundo que o cerca, além de ajudá-lo na elaboração de respostas para possíveis questionamentos cotidianos, existenciais etc. Por essa razão, é que Jean Foucambert (1994, p. 5) afirma que "ler significa ser questionado pelo mundo e por si mesmo, significa que certas respostas podem ser encontradas na escrita", e isso desperta no leitor um interesse pela leitura, fazendo com que ele não leia por obrigação, mas por curiosidade, por vontade de responder as perguntas que lhe inquietam.

Mesmo com todos os avanços tecnológicos e mudanças no contexto social, ler ainda é um problema para muitas pessoas. Embora a sociedade esteja cercada de todo tipo de leitura, o número de não-leitores é ainda assustador no Brasil. Segundo a pesquisa Retratos da Leitura no Brasil, realizada em 2015 pelo Instituto Pró-Livro (IPL), a população brasileira contava com 44\% de não-leitores e 56\% de leitores - aproximadamente 104,7 milhões de leitores.

A situação é preocupante e são inúmeros os fatores que contribuem para isso. Muitas crianças não têm o efetivo contato com os livros e, nesse caso, o motivo pode não ser apenas a falta de incentivo, embora este seja um problema Revista de Letras JUÇARA, Caxias - Maranhão, v. 03, n. 02, p. 143 - 159, dez. 2019| 145 
bastante recorrente na sociedade. Mas, dentre os motivos, temos: crianças que não vão à escola frequentemente (sem contar as que nunca foram); pais que não têm condições de comprar livros; pais que têm condições de comprar livros, mas não o fazem; escolas que não têm bibliotecas e/ou salas de leitura; escolas que contam com biblioteca, porém não oportunizam o contato dos alunos com os livros; ausência de projetos de leitura nas escolas; falta de pessoas que fomentem a leitura, seja na família, na escola, na comunidade etc.

De acordo com Demo (2006, p. 83), na maioria das vezes, o desgosto pela leitura "é alimentado pelas famílias, onde pouco ou nada se lê, ou não se valoriza a aprendizagem da leitura nos filhos". Por outro lado, se no ambiente familiar da criança o estudo é priorizado, se os pais têm o costume de comprar livros, jornais ou revistas, se o que a criança aprende é valorizado, é muito raro que elas não queiram estudar e praticar a leitura. E quando família e escola se unem, tornam-se uma base de sustentação para futuros leitores, pois "a criança que estiver bem vai melhorar e aquela que tiver problemas receberá a ajuda tanto da escola quanto dos pais para superá-los" (TIBA, 2002, p. 183).

Nota-se, porém, que muitas crianças não têm o incentivo à leitura em casa, o que acaba por "obrigar" a escola a ser a única responsável pelos processos educativos e de desenvolvimento do gosto pela leitura. Essa dupla obrigação imposta à escola faz com que, por vezes, o trabalho consista num processo falho, visto que enquanto a criança pode ter o constante contato com a leitura no espaço escolar, em casa ela pode não ter. Isto significa que a escola não fica impossibilitada de desenvolver esse trabalho com a criança, mas caso não conte com o apoio familiar, o aprimoramento da leitura da criança talvez se dê lentamente, dificultando a interação entre leitura e aluno.

Até aqui destacamos a importância da leitura em nosso cotidiano e do papel da família e da escola na formação leitora da criança, deixando claro que a educação de qualidade deve ser uma obrigação e não uma prioridade para poucos, e que o incentivo à leitura é a melhor iniciativa para formar leitores. A partir de agora, a figura do professor, no que diz respeito ao ato de ler, ganhará destaque, visto que ele, quando leitor ativo, é uma forte influência para que os seus alunos também sejam leitores ativos. 


\section{Competência leitora do professor como fator determinante para a formação de alunos leitores}

O professor é parte essencial à escola, para a organização do ensino. Uma escola sem esse profissional, não faria o mínimo sentido. Por isso é que este estudo tem o intuito de destacar o professor como o principal promotor da leitura, pois entendendo-o como mediador da leitura, é ele quem permitirá uma maior intimidade, proximidade, do aluno com os textos. E para que a leitura se torne uma prática efetiva, principalmente no âmbito escolar, ela depende de algumas condições, sendo uma das principais a própria preparação do professor, visto que ele é um "elemento chave na formação e no crescimento dos leitores ao longo da escolaridade" (SILVA, 2003, p. 20).

A escola tem como papel estimular a leitura, uma atividade que retoma o passado e se relaciona com as lembranças e conhecimentos do leitor. Porém, nem todo aluno terá essa capacidade interpretativa se não contar com a orientação de mediadores da leitura, aqui retratados pela figura do professor. Isto é, os alunos necessitam da orientação do docente, visto que é essencial nesse processo de desenvolvimento da leitura, mas para que isso se concretize, é também de extrema importância que os professores sejam competentes para ensinar, pois, como Simões (2006, p. 16) enfatiza, esse "é um processo de alto grau de complexibilidade e requer do professor competência técnico-pedagógica específica para que as dificuldades possam ser minimizadas". Isso só confirma a ideia de que ser professor não se limita apenas à transmissão de saberes, é necessário que ele seja capaz de detectar as dificuldades (suas e de seus alunos) para que possa superá-las, possibilitando que o processo de ensino-aprendizagem se dê de maneira produtiva.

\subsection{Dilemas da formação e da prática docente}

Ler não é uma tarefa fácil, uma vez que exige bastante esforço mental (e até físico), e muitas vezes pelo fato de exigir muito trabalho, algumas pessoas tendem a abandonar a ideia da leitura. No caso de formar alunos leitores, o esforço do professor é essencial e deve ser inacabável. Na teoria tudo pode parecer belo e 
ininterrupto, porém na prática é possível presenciar inúmeros fatores que permitem que o processo de desenvolvimento do hábito da leitura não seja contínuo.

Considerando o professor como principal formador de leitores, convém, primeiramente, destacar aqui como o não proveito do processo de formação acadêmica e a falta de leitura por parte dele é capaz de afetar a sua prática docente e, consequentemente, o aprendizado dos seus alunos. Acerca disso, Pedro Demo (2006) aponta que:

\footnotetext{
Um professor mal formado forma mal aluno. Esta visão pode ser apressada, pelo menos em parte, porque facilmente esquece que 0 professor não poderia ser "culpado", já que é vítima do mesmo sistema. Mas não se pode deixar de esclarecer que, se ele, não aprendeu a ler, não fará os alunos aprenderem a ler (DEMO, 2006, p. 72).
}

Todo professor já precisou passar pela escola como aluno e pode ter sido vítima do sistema de professores não leitores de sua época, o que de certa forma pode comprometer a sua prática leitora, influenciando diretamente, também, a sua prática docente. Sem contar os próprios cursos de licenciatura que, segundo Silva (1996, p. 11), "com exceção dos super-recentes programas de Literatura Infantojuvenil, tocam por cima a problemática relacionada com o ensino da leitura, gerando despreparo e lacunas na formação dos professores", o que nos permite entender que a prática leitora dos alunos não será tão importante, visto que a preocupação dos docentes será limitada a somente repassar conteúdos programáticos das disciplinas e diagnosticar através de atividades se os alunos de fato entenderam o que foi "apresentado" a eles durante a aula.

Por outro lado, pôr a culpa sempre no sistema não justifica a falta de interesse em relação à leitura, pois o professor comprometido com sua profissão, que deseja que os seus alunos aprendam algo e quer também aprender com os alunos, sabe que para isso é necessário acima de tudo ler, compreender o que lê, saber questionar o que é lido e se posicionar criticamente, ou seja, tudo baseia-se na leitura, não se pode negar.

Formar alunos leitores requer do professor interesse para que em seguida sejam elaboradas metodologias que facilitem o aprendizado desses alunos. Mas "sem uma qualificação sadia e sem uma dignificação intensa de nós mesmos, 
professores e principais personagens da educação e do ensino, é pura perda de tempo falar em transformação e avanço da escola brasileira" (SILVA, 2003, p. 20).

Um outro fator que pode prejudicar a prática docente e a promoção da leitura diz respeito à política de (des)valorização do professor. Como este profissional é visto no meio social contribui, e muito, para a sua prática docente, seja positiva ou negativamente. Infelizmente, a profissão não é tão valorizada quanto deveria ser e é por isso que está cada vez mais frequente presenciar as manifestações/greves dos professores em busca de melhorias na educação. De acordo com Silva (2003, p. 23), não é de hoje que a imagem do professor é reprimida, "os governos vêm, há décadas, desprezando o que há de mais nobre em educação: a dignidade do professor". São os baixos salários, os atrasos nos pagamentos, as cobranças de bons resultados quando os próprios governantes sequer se preocupam em investir na educação, acrescente-se a isso as reformas educacionais que mudam radicalmente.

A política salarial dos professores, embora já bastante conhecida no cenário brasileiro, merece destaque aqui. Não dá para cobrar empolgação do professor ao ministrar suas aulas quando ele sabe que em sua conta bancária não consta nenhum centavo para garantir a sua "sobrevivência" ou até mesmo pagar as cópias das provas e/ou atividades que deseja dispor aos seus alunos. Infelizmente, é esta realidade desmotivadora que circunda a vida dos professores. O salário deveria servir não só como pagamento pelo trabalho ofertado, mas como uma forma de incentivo, o que geraria melhorias no ensino.

Já que o presente estudo trata da prática de leitura do professor e a formação de alunos leitores, por que não dizer que todos esses fatores relacionados à situação precária do professor não afetam também as suas práticas leitoras? Silva (2003) nos apresenta quatro condições essenciais para que um sujeito seja capaz de praticar a leitura na sua vida, são elas: "entender o código, ter um aparato ocular em ordem, ter acesso a diferentes textos, ter tempo e energia física para tal" (p. 11). Se relacionarmos essas condições ao professor, podemos eliminar de princípio as três primeiras, pois são bem (ou relativamente) atendidas. Quanto ao tempo, a carga horária semanal do professor é desgastante, muitos ministram aulas nos três turnos por exigência da profissão ou têm outros empregos como forma de aumentar a renda, pois o salário docente nem sempre é capaz de

Revista de Letras JUÇARA, Caxias - Maranhão, v. 03, n. 02, p. 143 - 159, dez. 2019|149 
suprir com todas as necessidades do professor. Assim considerando, a falta de tempo garante o desgaste físico (e até mesmo emocional), de forma que ao chegar em casa o docente só pense em descansar.

\begin{abstract}
Uma boa aula depende de leituras, de pesquisas, de organização de conteúdos e atividades, de acompanhamento dos alunos dentro e fora da sala de aula etc. Se for verdade que a pressa é inimiga da perfeição e eterna namorada da improvisação, então não há como falar em qualidade de ensino sem que ao professor sejam fornecidas as condições objetivas para a realização do seu trabalho (SILVA, 2003, p. 12).
\end{abstract}

Segundo Lajolo e Zilberman (2002, p. 26): “Já se conhece nesse ponto a pouca - ou quase nula - preocupação das autoridades com a difusão da leitura e da escrita, habilidades essenciais aos cidadãos de um Estado que se deseja moderno, como ocorria nos países europeus, que começavam a investir na educação popular". Por essa razão, nota-se que até mesmo os sistemas políticos acreditam que a educação é totalmente capaz de mudar determinadas situações, sejam elas sociais, políticas, econômicas etc., e por serem conhecedores disso é que buscam investir o mínimo nos recursos necessários para o processo educativo.

$\mathrm{O}$ ato de ler destaca-se como fundamental nessa luta por direitos. Eis que surge o professor, com o seu papel de mediar leituras. Nesse momento de ensino, o profissional ajuda os alunos não somente a lerem, mas interpretarem tudo o que leem, a relacionarem as suas leituras com suas vivências, a criticarem situações sociais, políticas e econômicas, ou seja, o professor torna, assim, o aluno um leitor ativo e crítico.

\title{
3 A influência do professor leitor ativo no processo de ensino-aprendizagem da leitura
}

É sabido que o papel do professor é possibilitar que os alunos adquiram experiências no que se refere à aprendizagem, principalmente da leitura e da escrita, para tanto, ressalta-se a necessidade de que a leitura seja imensamente presente na vida do docente; afinal, até as suas aulas são ministradas mais harmoniosamente quando ele gosta de ler e pratica esse hábito com frequência. 
Quando leitor ativo, o professor apresenta um perfil diferenciado: ele lê por prazer, ele não só decifra códigos, bem como questiona tudo o que por ele é lido; tem melhor capacidade para argumentar, discutir sobre diferentes tipos de assuntos; sabe detectar e solucionar problemas com facilidade; sabe defender um ponto de vista, entre tantos outros benefícios.

A leitura é responsável por contribuir significativamente para a formação do indivíduo. Assim sendo, o professor, por sua vez, pode ser um ótimo mediador desse processo de leitura. Antes de tudo, é importante que se deixe claro aos alunos que $o$ ato de ler não é uma tarefa a ser realizada somente na escola. Para tanto, cabe ao professor desenvolver estratégias de incentivo à leitura. Mas, segundo Demo (2006):

Os professores tanto da educação básica quanto superior, de modo geral queixam-se de que os alunos leem cada vez menos e sequer "sabem" ler. A prova mais cabal disso, porém, é que os professores em grande parte, também não leem, são incapazes de elaborar textos próprios, não pesquisam, não produzem conhecimentos (p. 48).

São muitas as hipóteses existentes acerca dessa questão, mas, é preferencial que acreditemos que os alunos leem, sim, e podem ainda escolher as suas leituras. É inaceitável, portanto, afirmar que os alunos não leem ou não sabem ler, pois todos somos capazes de ler algo, inclusive a nós mesmos. Eles (os alunos) talvez leiam o que outras pessoas (principalmente, os professores) não apontam como uma leitura importante. As leituras realizadas pelos alunos não podem ser desprezadas, tudo depende da motivação que ele recebe.

Se os alunos não gostam de ler o que lhes é apresentado pelo professor, talvez seja este o momento de conhecer mais as características da geração que esses alunos pertencem e se aproximar um pouco mais da realidade por eles vivenciada. Por exemplo, se o professor está a par de algumas expressões próprias do vocabulário virtual, por que não buscar textos com esse tipo de expressões para analisar com os alunos? O docente não é, nem deve se considerar, o detentor de todo o conhecimento. Não é vergonhoso que os alunos saibam que ele desconhece algumas (tantas) coisas. Afinal, o seu dever não é somente ensinar, muito menos o dos alunos é somente aprender, embora (infelizmente) muitos professores ainda 
estejam presos a esse pensamento. Quanto a isso, Marcos Bagno (2006) afirma que "Não existe professor, por mais culto e bem informado que seja, que não tenha sempre o que aprender, não é? A verdade não é privilégio de ninguém!" (p. 49).

O professor precisa refletir sobre as suas atitudes tanto em relação a sua própria prática de leitura quanto à prática docente, pois a "não prática" de leitura dos alunos pode ser resultado da falta de incentivo do professor, como bem enfatiza Lajolo (2005):

O desencontro literatura/jovens que explode na escola parece mero sintoma de um desencontro maior, que nós - professores - também vivemos. Os alunos não leem, nem nós; os alunos escrevem mal e nós também. Mas, ao contrário de nós, os alunos não estão investidos de nada. $\mathrm{E}$ o bocejo que oferecem à nossa explicação sobre o realismo fantástico de Incidente de Antares ou sobre a metalinguagem de Memórias Póstumas de Brás Cubas é incômodo e subversivo, porque sinaliza nossos impasses (p. 16).

Não se pode cobrar leituras dos alunos quando o próprio professor não tem uma boa relação com a leitura. Se um texto não apresenta significado nenhum para ele, de nada adianta levar o mesmo texto para os alunos, uma vez que para eles também não fará sentindo algum, mesmo que respondam satisfatoriamente as questões das atividades propostas em sala de aula.

O aluno tem de compreender a leitura como uma prática prazerosa, mas o que mais vigora nas escolas é a necessidade de comprovar ou avaliar as leituras dos alunos, ou seja, a leitura não é realizada por prazer, o aluno não lê espontaneamente. Pelo contrário, ele lê sabendo que haverá uma atividade ou uma prova para testar os seus conhecimentos. Infelizmente, essa forma de avaliar leituras faz parte do processo de escolarização, permitindo que a escola não tenha como objetivo principal formar alunos leitores.

Segundo os Parâmetros Curriculares Nacionais (1997), é responsabilidade da escola tornar os alunos bons leitores, desenvolvendo não só a capacidade de ler, mas o gosto e o compromisso com a leitura. Para que assim seja, a instituição deve se esforçar em fazer com que os seus alunos também se esforcem para aprender a ler, ou seja, é necessário que os alunos entendam a leitura como "algo interessante e desafiador, algo que, conquistado plenamente, dará autonomia e independência" (p. 58). É função da escola propagar conhecimentos à respeito do

Revista de Letras JUÇARA, Caxias - Maranhão, v. 03, n. 02, p. 143 - 159, dez. 2019| 152 
valor da leitura. Sendo assim, o professor é quem deve mediar esse processo e como todo mediador de leituras, é importante que ele tenha uma boa relação com os livros, tenha uma bagagem repleta de diferentes tipos de leitura, isto é, pratique efetivamente a leitura. Só quem é um bom leitor é digno de formar bons leitores, ou seja, um profissional que não tem um bom preparo, que não se preocupa em manter contato com os textos ao seu redor, que desconhece os recursos que podem contribuir para a formação leitora dos alunos, não se encaixa nessa categoria de formador de leitores.

Na perspectiva de Silva (2003, p. 28), caso o professor "não seja um leitor assíduo, rigoroso e crítico, são mínimas ou nulas as chances de que possa fazer um trabalho condigno na área da educação e do ensino da leitura", isto é, o profissional precisa ser conhecedor da leitura, ter um bom repertório, para que esteja apto a disseminar leituras. Além disso, é essencial que ele alimente a sua capacidade de produzir textos próprios com o intuito de fazer com que seus alunos também elaborem textos, pois eles aprendem com os bons exemplos e se o professor deseja obter bons resultados, começar o trabalho por si mesmo pode ser uma ótima solução. Caso contrário, ele torna o processo de ensino-aprendizagem insatisfatório "fingindo que ensina e lê, e os seus alunos fingindo que aprendem e leem" (Ibidem).

A forma de ensinar reflete diretamente na aprendizagem dos alunos, por isso é certo afirmar que o professor sendo um espelho de leituras, sendo um bom leitor, poderá formar, sim, alunos leitores. Da mesma forma que se ele for um mau leitor, formará maus leitores. Torna-se necessário que o docente esteja em constante processo de leitura e aprendizado, o que comprova que "até mesmo a atualização dos professores fica na dependência de leituras diversas, e, por que não dizer a preparação e reformulação de seus programas de ensino" (SILVA, 1996, p. 33), ou seja, não dá para negar a importância da leitura para as práticas docentes. A forma pela qual o professor encara as suas leituras é que vai orientar a elaboração até mesmo dos seus planos de aula.

Inúmeros são os estudos que destacam a importância de o professor ser leitor para formar alunos leitores. Sendo conhecedor disso, Richard Bamberger (1995) realizou uma pesquisa na Áustria e como resultado pôde constatar que o 
professor tem, sim, a capacidade de influenciar seus alunos a lerem. Segundo os resultados obtidos com a pesquisa, as crianças que leem excessivamente:

a) Têm geralmente um relacionamento muito bom com o professor, o qual, por sua vez, leitor entusiasta, procura fazer com que os alunos experimentem na leitura um prazer idêntico ao seu;

b) Frequentaram aulas de professores interessados e informados, que possuíram boa provisão de material de leitura;

c) Foram "induzidos à leitura" por um contínuo contato com os livros e métodos especiais de ensino moderno da leitura (BAMBERGER, 1995, p. 20).

Ou seja, o professor precisa instigar os seus alunos, atiçar a curiosidade deles, não esquecendo-se de trabalhar a si mesmo, primeiramente. Tratando-se da situação do professor brasileiro, é perceptível a necessidade de melhorias, visto que as próprias condições de trabalho não são favoráveis ao ensino. Além disso, alguns professores ainda se apegam à relação de causa e efeito, creem que o aprendizado do aluno só pode melhorar se a escola dispor de determinados equipamentos, por exemplo, se na escola houver computadores e acesso à internet, os alunos se interessarão mais no que é proposto nas aulas.

A problemática encontra-se, portanto, na ideologia pregada pelo professor e não na metodologia. São as ideias por ele defendidas que encaminharão a sua prática docente. Afinal, de nada adianta inovar o ensino, utilizar novas metodologias, se ele - o professor - não se preocupar em despertar o interesse dos alunos às suas aulas e o pior que pode acontecer é o professor colocar a culpa somente nos alunos e na falta de recursos da escola, e esquecer que ele também é parte essencial para que os alunos tenham sede de aprender.

Outro problema diz respeito ao apego ao livro didático. Muitos docentes ainda confundem a função desse manual e o utilizam do minuto inicial ao minuto final de suas aulas. Em relação às práticas de leitura e produção textual em sala de aula, Rocha (2013, p. 111) afirma que "resume-se a atividades propostas pelos manuais, apresentando-se, muitas vezes, de forma descontextualizada trazendo apenas trechos retirados de obras", o que acaba comprometendo a criatividade do aluno ao limitar seus conhecimentos acerca tanto de fatores linguísticos quanto a própria compreensão literária. Pois, ao utilizar o livro didático como principal 
metodologia, o professor faz com que o processo de ensino-aprendizagem se dê de maneira fragmentada, da mesma forma que o livro didático traz os conteúdos.

Silva (2003, p. 41-42) enfatiza que se limitar apenas ao uso do livro didático gera barreiras durante o processo de aprendizagem e que isso não se refere somente aos conteúdos pragmáticos, mas também ao desprezo dos textos e dos diferentes tipos de se ler. Leitura engloba interação, ou seja, é de extrema importância que ela possa interagir com o leitor, pois quando uma leitura faz sentido e conversa com o universo particular do leitor, o interesse e a curiosidade são despertados nele, e isso raramente se consegue através do livro didático.

\subsection{A seleção de textos e a promoção da leitura}

Quando se trata de atividades que envolvam a leitura, sabe-se que deve haver um bom planejamento por parte do professor. É preciso que ele conheça a turma para que posteriormente prepare suas aulas da melhor forma possível. É indicado que se faça um diagnóstico da turma, isto é, saber qual a faixa etária dos alunos, identificar as principais dificuldades por eles apresentadas em relação à prática de leitura e escrita, detectar quais os tipos de textos mais lidos etc., ou seja, conversar com os alunos. Manter diálogos é essencial, serve não somente para discutir gostos e habilidades, mas também para compartilhar ideias e experiências. Fazendo isso, o professor terá mais facilidade ao selecionar textos, pois irá se preocupar em levar para a sala de aula textos que estejam à altura dos alunos, de forma que possam dialogar com os objetivos das aulas.

O educador, segundo Martins (1994, p. 34), ao ensinar a prática da leitura aos seus alunos, deve criar condições para que eles realizem as suas próprias aprendizagens, "conforme seus próprios interesses, necessidades, fantasias, segundo as dúvidas e exigências que a realidade lhe apresenta". Isso não quer dizer que basta possibilitar o acesso aos livros, muito menos que o aluno só irá ler o que quiser. É preciso que o professor ensine-os a escolher bem as leituras, mas com cuidado, é claro, pois da mesma forma que o professor pode aproximar as crianças do mundo da leitura, ele também pode afastá-las ao indicar leituras inadequadas. 
Sendo assim, "o compromisso do professor é enorme, porque na prática, é ele que seleciona o que o aluno vai ler" (DEMO, 2006, p. 72), ou seja, ainda que o aluno goste de um determinado tipo de leitura, gênero textual, ele não terá total liberdade para escolher sempre o que quer ler, isso porque em muitas escolas 0 que o aluno gosta de ler não é o mesmo que solicita o planejamento, muito menos encontra-se de acordo com as exigências das aulas, o que acaba limitando as leituras dos alunos às escolhas dos professores.

No intuito de evitar que ocorra a morte do leitor, o professor pode dinamizar as práticas de leituras. Optar por levar textos que são considerados difíceis pelos alunos, para que se possa orientá-los, permite que eles entendam que nenhuma leitura é impossível e que realizar apenas uma leitura de um mesmo texto não nos possibilita compreendê-lo, ou seja, diversificar os textos é uma forma dinâmica de mostrar que não é leitor aquele que lê apenas um gênero.

Infelizmente, alguns professores não têm a preocupação de conhecer profundamente a turma de leitores, o que permite que o seu ensino seja baseado no improviso ou até mesmo na imposição de atividades de leitura sem uma real finalidade.

Nota-se que, de uma forma ou de outra, a escola ainda limita muito as leituras dos alunos, mostrando-lhes apenas a leitura reduzida à resolução de atividades. E a aprendizagem para ser considerada adequada não deve ser limitada à reprodução de conteúdos, pensamentos e ideias, e muito menos se restringe apenas ao ambiente escolar, uma vez que o aluno deve aprender para a vida, pois a aprendizagem se dá tanto dentro quanto fora da escola.

Sendo assim, a missão de formar alunos leitores deve consistir numa tarefa incansável e contínua. Criar rotinas de leituras, possibilitar o acesso aos livros, desenvolver o gosto pela leitura etc., são responsabilidades da escola/do professor. Tendo isso como princípio, pode-se dizer que a escola formará, sim, alunos leitores.

A partir das considerações até aqui apresentadas, destaca-se a necessidade de uma política de formação de leitores no âmbito escolar, mas para que a leitura consista numa prática efetiva, a escola e os alunos dependem, entre outros aspectos, de professores que mantenham um compromisso fiel com a leitura e entendam-na como um fator determinante para a formação de seus alunos. $A$ influência do professor tem papel decisivo no ensino da leitura, principalmente se 
pensarmos na capacidade de compensação das desigualdades a que muitas crianças estão sujeitas, cujas famílias não estimulam ou não têm condições de proporcionar o acesso ao mundo da leitura.

Com o intuito de formar alunos leitores, sugere-se as seguintes alternativas metodológicas que podem ser utilizadas pelos professores em sala de aula: 1 . Instigar o conhecimento prévio dos alunos; 2. Ensiná-los a fazer perguntas ao texto e levantar hipóteses e previsões sobre a leitura realizada; 3. Realizar leituras compartilhadas; 4. Fazer uso dos diferentes tipos de leitura (silenciosa, coletiva, oral, individual e compartilhada); 5. Solicitar trabalhos em que os alunos precisem ler instruções e saber segui-las adequadamente; 6 . Colocar os alunos no lugar do professor, fazendo com que eles se responsabilizem por incentivar os outros alunos a praticarem a leitura; 7 . Utilizar recursos e textos variados; 8 . Estimular a produção de textos para a construção de livros pelos próprios alunos; 9. Cercar o aluno de leitura, pois como bem afirma Solé (1988, p. 52), o texto escrito deve estar presente "de forma relevante na sala de aula - nos livros, nos cartazes que anunciam determinadas atividade".

Tudo isso só tende a contribuir positivamente para a formação de leitores. Convém lembrar que muitas crianças só têm contato com os livros ou com a leitura na escola e para a maioria delas, o âmbito escolar consiste num local desmotivante, pois se deparam com metodologias tradicionais e monótonas. Devido a isso, o desenvolvimento da leitura dos alunos acaba que comprometido, uma vez que estes leem apenas para tirar informações superficiais do texto, e acabam não se aprofundando na leitura, o que impede ou limita a construção de significados. Por isso é tão importante que o professor passe por um processo de amadurecimento metodológico, pois ele torna-se mais apto a dinamizar suas aulas, de forma que os alunos sintam-se cada vez mais motivados a participar das aulas.

\section{Considerações finais}

A educação brasileira enfrenta inúmeras dificuldades e com a prática da leitura também não é diferente. As exposições feitas neste trabalho, com base nas bibliografias utilizadas, comprovam o quão importante é a prática da leitura para a 
formação do indivíduo e o quanto isso reflete na sociedade. E o aprimoramento dessa prática se dá através do incentivo, seja no contexto familiar ou escolar.

Dentre os profissionais atuantes na escola, o aluno tem contato mais próximo com o professor. Assim sendo, este estudo enfocou o perfil desse profissional como leitor, mostrando que ele tem forte influência para a formação de alunos também leitores, e leitores ativos.

Para se desenvolver o gosto dos alunos pela leitura, o professor tem de trabalhá-la de maneira prazerosa em sala de aula, além disso é essencial que se dê atenção às dificuldades dos alunos, estimulá-los a ler, mostrar a importância e o benefício dessa prática para eles. Professores comprometidos com a leitura têm mais facilidade para: identificar os problemas dos alunos e buscar a melhor forma de selecioná-los, selecionar textos e metodologias que mais se encaixam na sua prática de ensino, despertar nos alunos o interesse pela leitura, mostrar para eles o poder da palavra quando esta é carregada de muita leitura e conhecimentos etc.

Para a obtenção de melhores resultados, o interesse em aprender também depende dos alunos, mas é necessário que alguém lhes oriente, mostrando o caminho a ser seguido. Mesmo que a família incentive, é na escola que os alunos devem vivenciar práticas leitoras, entenderem a importância da leitura para as suas vidas e tornarem-se leitores não só ativos, mas também críticos.

Esta pesquisa é relevante por contemplar o papel do professor leitor na formação de novos leitores, uma vez que muitas pesquisas relacionadas à leitura direcionam-se apenas para os seus conceitos e à busca de alternativas para o hábito de leitura no aluno. Possibilita, ainda, uma reflexão acerca das práticas pedagógicas e metodológicas para o desenvolvimento da leitura no aluno, permitindo perceber que a falta de interesse dos alunos para com o universo da leitura conta com desacertos que têm soluções e que o professor é capaz de superar tais dificuldades e tornar seus alunos leitores ativos. Ressalta-se que este estudo não pretende esgotar a temática, mas, sim, contribuir para a construção de novas reflexões e pesquisas, visando a melhoria no ensino e a promoção da leitura.

\section{Referências bibliográficas}

BAMBERGER, Richard. Como incentivar o hábito de leitura. São Paulo: Ática, 2005.

Revista de Letras JUÇARA, Caxias - Maranhão, v. 03, n. 02, p. 143 - 159, dez. 2019 | 158 
BAGNO, Marcos. Pesquisa na escola: o que é, como se faz. 20ª . ed. São Paulo: Edições Loyola, 2006.

BRASIL. Secretaria de Educação Fundamental. Parâmetros Curriculares Nacionais: língua portuguesa. Brasília: MEC/SED, 1997.

DEMO, Pedro. Leitores para sempre. 2ª ${ }^{\mathrm{a}}$. ed. Porto Alegre: Editora Mediação, 2006.

FOUCAMBERT, Jean. A leitura em questão. Porto Alegre: Artes Médicas, 1994.

LAJOLO, M. Do mundo da leitura para a leitura do mundo. São Paulo: Editora Ática, 2005.

LAJOLO, M; ZILBERMAN, R. A leitura rarefeita: leitura e livro no Brasil. São Paulo: Ática, 2002.

A formação da leitura no Brasil. São Paulo: Editora Ática, 1999.

MARTINS, Maria Helena. O que é leitura. 19ª. ed. São Paulo: Brasiliense, 1994.

ROCHA, Marinalva Aguiar T. Moinho de leitura literária: disseminando a literatura infanto-juvenil no ensino fundamental. In: CARVALHO, Maria; MOTTA, Cláudia Maria M. (orgs.) O linguístico e o literário: cruzando fronteiras. São Luís: Editora UEMA, 2013, p. 111-130.

SILVA, Ezequiel Theodoro da. Conferências sobre leitura - trilogia pedagógica. São Paulo: Autores Associados, 2003.

2003.

Leitura em curso - trilogia pedagógica. São Paulo: Autores Associados,

. Unidades de Leitura - trilogia pedagógica. São Paulo: Autores Associados, 2003.

$\mathrm{O}$ ato de ler: fundamentos psicológicos para uma nova pedagogia de leitura. 7ª . ed. São Paulo: Cortez, 1996.

SIMÕES, Darcilia. Considerações sobre a fala e a escrita: fonologia em chave. São Paulo: Parábola, 2006.

SOLÉ, Isabel. Estratégias de leitura. 6ª ed. Porto Alegre: Artmed, 1998.

TIBA, Içami. Quem ama, educa! São Paulo: Editora Gente, 2002.

Data da Submissão:15/11/2019

Data da Aprovação: 09/12/2019

Revista de Letras JUÇARA, Caxias - Maranhão, v. 03, n. 02, p. 143 - 159, dez. 2019| 159 